\title{
The ulnar head of the pronator teres muscle originating from the third head of the biceps brachii: a very rare case
}

\author{
Ł. Olewnik'1 , N. Zielinska' ${ }^{1}$, B. Szewczyk'1 ${ }^{1}$ R.S. Tubbs ${ }^{2-7}$ \\ ${ }^{1}$ Department of Anatomical Dissection and Donation, Medical University of Lodz, Poland \\ 2Department of Anatomical Sciences, St. George's University, Grenada, West Indies \\ ${ }^{3}$ Department of Neurosurgery, Tulane University School of Medicine, New Orleans, LA, United States \\ ${ }^{4}$ Department of Neurology, Tulane University School of Medicine, New Orleans, LA, United States \\ ${ }^{5}$ Department of Structural and Cellular Biology, Tulane University School of Medicine, New Orleans, LA, United States \\ ${ }^{6}$ Department of Surgery, Tulane University School of Medicine, New Orleans, LA, United States \\ ${ }^{7}$ Department of Neurosurgery, Ochsner Medical Centre, New Orleans, LA, United States
}

[Received: 2 October 2021; Accepted: 14 October 2021; Early publication date: 9 November 2021]

\begin{abstract}
The biceps brachii is located in the anterior compartment of the arm, which can show numerous morphological variations. During anatomical dissection, an interesting additional muscle was found: the third head of the biceps brachii originated from the short head of the same muscle. The $97.77 \mathrm{~mm}$ long muscle belly was directed medially over the arm and then passed into the common tendon $(15.97 \mathrm{~mm})$, which thereafter split into aponeurosis and tendon. The $26.33 \mathrm{~mm}$ aponeurosis passed and joined the fascia of the forearm. The tendon of the third head of the biceps brachii then gave rise to the ulnar head of the pronator teres muscle. Such an accessory structure could cause neurovascular compression involving the brachial artery and median nerve. Knowledge of the morphological variability of this region is essential not only for anatomists but also for clinicians. (Folia Morphol 2023; 82, 1: 225-230)
\end{abstract}

Key words: anatomical variations, biceps brachii, third head

\section{INTRODUCTION}

It seems that the biceps brachii (BB), next to the plantaris or palmaris longus, is one of the most morphologically variable muscles $[29,30]$. Standard anatomy books describe it as consisting of two heads, short and long [27].

There are frequent morphological variations of the BB involving both the proximal and distal attachments, and also additional heads $[2,6,9,10$, $15,17,19,21-23,36,38,39,44,48]$. Arguably the greatest degree of morphological variation concerns the number of supernumerary heads, which can range from three to five $[2,17]$. Accessory heads can also arise from the deltoid muscle, the pectoralis major, the coracoid process or the humerus $[4,6,8,9,12$, $16,17,22]$. The supernumerary heads of the BB have functional and clinical implications arising from their potential to influence certain muscle functions or induce symptoms of neurovascular compression [6].

The present case report describes a very rare variant of the third head of the $\mathrm{BB}$, the tendon of which gives origin to the ulnar head of the pronator teres. The brachial artery and the median nerve (MN) could be compressed between the tendon and the aponeurosis.

Address for correspondence: $Ł$. Olewnik, DPT, PhD, Ass. Prof., Department of Anatomical Dissection and Donation, Medical University of Lodz, ul. Żeligowskiego 7/9, 90-136 Łódź, Poland, e-mail: lukasz.olewnik@umed.lodz.pl

This article is available in open access under Creative Common Attribution-Non-Commercial-No Derivatives 4.0 International (CC BY-NC-ND 4.0) license, allowing to download articles and share them with others as long as they credit the authors and the publisher, but without permission to change them in any way or use them commercially. 

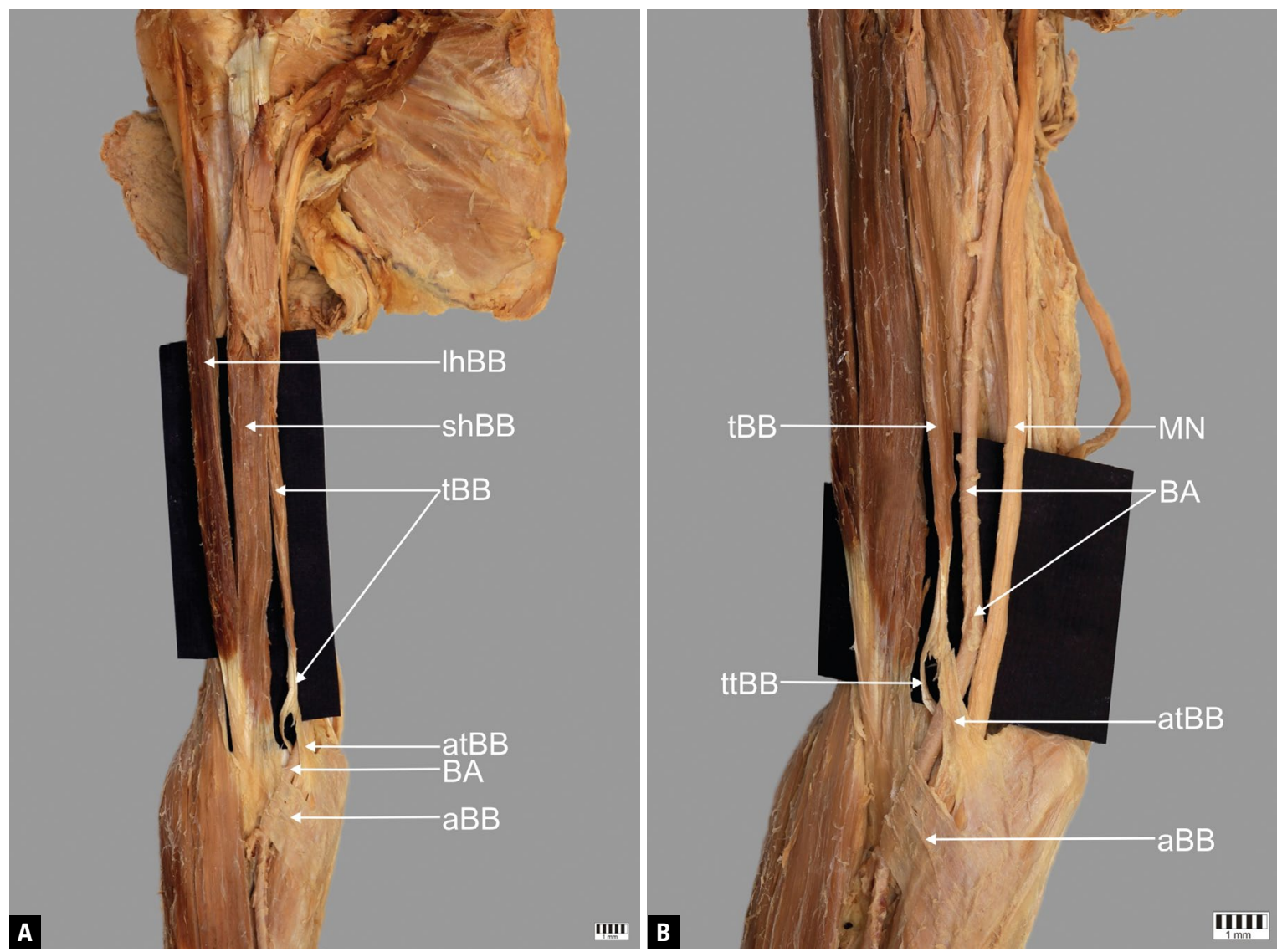

Figure 1. A, B. A third head of the biceps brachii; lhBB — long head of the biceps brachii; shBB — short head of the biceps brachii; tBB — third head of the biceps brachii; atBB — aponeurosis of the third head of the biceps brachii; BA — brachial artery, aBB — aponeurosis of the biceps brachii; $\mathrm{ttBB}$ - tendon of the third head of the biceps brachii; $\mathrm{MN}$ - median nerve.

\section{Ethical approval and consent to participate}

The cadavers belonged to the Department of Anatomical Dissection and Donation, Medical University of Lodz, Poland.

\section{CASE REPORT}

A female cadaver, 77 years old at death, was subjected to routine anatomical dissection for research and teaching purposes at the Department of Anatomical Dissection and Donation, Medical University of Lodz, Poland. The right upper limb underwent traditional anatomical dissection and a morphological variant of the third head of the BB was found [33-35, 45-47]. The next stage of the investigation involved a detailed assessment of this structure. The third head of the BB originated from the shBB. The $97.77 \mathrm{~mm}$ long muscle belly was directed medially over the arm and then passed into the common tendon $(15.97 \mathrm{~mm})$, which then split into aponeurosis and tendon (Fig. 1). The myotendinous junction was $3.72 \mathrm{~mm}$ wide and $1.19 \mathrm{~mm}$ thick. The $26.33 \mathrm{~mm}$ aponeurosis passed and joined the fascia of the forearm (Fig. 1).

The brachial artery and the MN ran between the aponeurosis and the tendon. The diameter of the brachial artery between the aponeurosis and the tendon was $4.78 \mathrm{~mm}$, and the diameter of the MN was $5.03 \mathrm{~mm}$. The $69.29 \mathrm{~mm}$ tendon then gave rise to the ulnar head of the pronator teres muscle (Fig. 2).

An electronic calliper (Mitutoyo Corporation, Kawasaki-shi, Kanagawa, Japan) was used for these measurements. Each measurement was repeated twice with an accuracy of up to $0.1 \mathrm{~mm}$.

No other morphological variations were found.

\section{DISCUSSION}

The BB is characterised by numerous morphological variations that concern both its proximal and distal attachments, and the number of bellies $[2,4-6$, $17,22,29,37]$.

Knowledge of the embryological development of the muscle elucidates the occurrence of accessory 


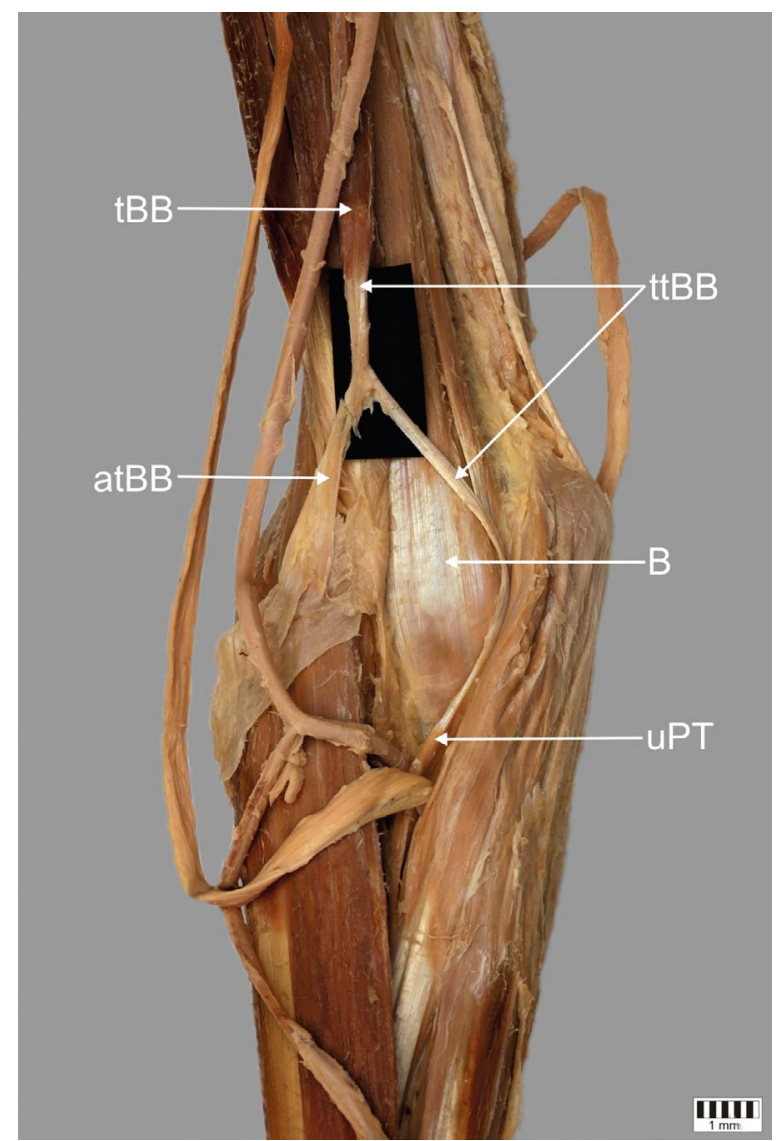

Figure 2. Distal part of the third head of the biceps brachii and proximal part of the anterior compartment of the forearm; tBB third head of the biceps brachii; ttBB - tendon of the third head of the biceps brachii; atBB - aponeurosis of the third head of the biceps brachii; B - brachialis muscle, uPT — ulnar head of the pronator teres muscle.

heads of the BB. The BB, coracobrachialis, and brachialis muscles are intimately fused during very early stages and probably arise from a common premuscular mass. At this early stage, the two heads of the BB are close together and only become separated by the later growth of the scapula. The three muscles can be recognised in embryos measuring 14-16 mm in length, and the long tendon of the caput longum can be recognised in embryos $14 \mathrm{~mm}$ long. The distal end of the common muscle mass differentiates later than the proximal end [7]. The third, fourth and fifth heads of the BB are believed to arise from the brachialis muscle. In such instances, the distal attachment is translocated from the ulna and radius [40].

The third head of the BB was first described by Theile [41], Wood [42] and Macalister [26]. Many subsequent authors have reported cases and the incidence of additional heads. The most common variation of the $B B$ is a third head, occurring in $4.2 \%$ to $19.8 \%$ $[2,5,6,12,22,29,37,40,42]$. Many cases of third heads have been described. Both Macalister [26] and Wood [42] described a separate slip from the coracobrachialis continuous with the short head of the BB. Macalister [26] also found a third head arising directly from the brachialis muscle and this head crossed the brachial artery; the third head also originated from the deltoid muscle and from the outer tuberosity. Testut [40] reported acromial, labial and pectoral supernumerary heads of the BB. Kosugi et al. [22] found three- and four-headed BB muscles and created a classification system. Type I, three heads, was divided into distinct subtypes. Subtype a was characterised by an origin on the shaft of the humerus (between the coracobrachialis and brachialis muscles). Subtype b was proximally attached to the medial brachial intermuscular septum. Subtype $\mathrm{c}$ included cases with different locations of origin, for example from the tendinous part of the pectoralis major, deltoid muscle, or greater tubercle.

Rodriguez-Niedenfuhr et al. [37] distinguished three various origins of the third head of the BB. The first type, originating from the antero-medial surface of the humerus, was the most common (frequency $9 \%$ ). It was characterised by an inferomedial head distally fused with the insertion of the coracobrachialis muscle. The second type occurred in 1.5\% of the population; the superior humeral head was attached to the surface of the humerus between the lesser tubercle and the proximal attachment of the brachialis and coracobrachialis muscles. The third type, occurring in only $0.3 \%$ of cases, was an infero-lateral humeral head. Its origin was located on the lateral intermuscular septum between the proximal attachment of the brachioradialis muscle and the insertion of the deltoid muscle [38].

In the third head of the BB we have described, a proximal attachment on the short head of the $B B$ headed towards the medial side of the arm and the muscle belly turned into a common tendon and then split into two parts: the aponeurosis, which connected to the fascia of the forearm, and the tendon, which passed directly into the ulnar head of the pronator teres muscle. A similar case was described by Macalister [25], where the accessory third head originated from the upper border of the pronator teres.

The atypical course of the aponeurosis and tendons could cause pressure on the brachial artery and 
the MN. Entrapment of the brachial artery between the aponeurosis and the tendon of the BB could cause acute or chronic intraluminal arterial thrombosis, further leading to acute distal embolisation.

Other pathologies could result from compression the MN $[3,27]$. For example, when the $M N$ is compressed by the pronator teres heads, ulnar and humeral, the result is pronator teres syndrome [32] manifested by pain in the volar forearm region and weakness. Another pathology, referred to as the most common, is carpal tunnel syndrome characterised by pain, numbness and paraesthesia's, especially in the fingers, though it can also radiate up the affected arm $[11,27]$. MN compression in the arm region is much less frequent. It can be associated with Struthers' ligament and is known as supracondylar process syndrome [20,32]. Additional structures such as a third head of the biceps brachii can also lead to MN neuropathy [43]. An accessory head of the coracobrachialis muscle is another example, but it occurs at the level of the lateral cord of the brachial plexus $[13,14,24,34,35]$.

In this case, we are dealing with an even higher likelihood of pressure, which could perturb the innervation of most of the forearm muscles. A typical symptom is pain in forearm reversal movement and sensory disturbances in the fingers and the inner surface of the hand.

A fourth head is much rarer than a third head $[1,12,22,37]$. Kosugi et al. [22] report that the fourth head of the BB can originate from the pectoralis major tendon or the greater tubercle or articular capsule. A fifth head of the BB has very rarely been described [37].

Accessory heads of the BB can increase the risk of pathologies such as bicipital injury. Moreover, such morphological variations are clinically significant for surgeons, especially for orthopaedics. A possible change in the biomechanical forces applied to the humerus should be considered among patients with humeral fracture with bone displacement. It is worth mentioning that additional structures usually entail some neurovascular compression. An accessory head of the BB can potentially compress the brachial artery, musculocutaneous nerve, and MN, leading to pain and various nerve compression syndromes.

\section{CONCLUSIONS}

The $\mathrm{BB}$ is highly morphologically variable. The case described is unique in that it gives origin to the ulnar head of the pronator teres and could also cause pressure on the brachial arteries.

\section{Acknowledgements}

The authors sincerely thank those who donated their bodies to science so that anatomical research could be performed. Results from such research can potentially increase mankind's overall knowledge that can then improve patient care. Therefore, these donors and their families deserve our highest gratitude (Iwanaga et al. [18]).

\section{Conflict of interest: None declared}

\section{REFERENCES}

1. Adachi B. Beitrage zur anatomie der Japaner. XII. Die statistic der muskelvarietten. Z Morphol Anthr. 1909: 261-312.

2. Al-Kushi G. Anatomical study of the third head of biceps brachii muscle and its innervation by median nerve in human dissection. J Clin Med Res. 2013; 5(4): 47-52, doi: 10.5897/jcmr12.017.

3. Andreisek G, Crook DW, Burg D, et al. Peripheral neuropathies of the median, radial, and ulnar nerves: MR imaging features. Radiographics. 2006; 26(5): 1267-1287, doi: 10.1148/rg.265055712, indexed in Pubmed: 16973765.

4. Anson B. An Atlas of Human Anatomy, 2nd ed. WB Saunders Company, Philadelphia 1963.

5. Asvat R, Candler P, Sarmiento EE. High incidence of the third head of biceps brachii in South African populations. J Anat. 1993; 182 (Pt 1): 101-104, indexed in Pubmed: 8509293.

6. Ballesteros LE, Forero PL, Buitrago ER. Evaluation of additional head of biceps brachii: a study with autopsy material. Folia Morphol. 2014; 73(2): 193-198, doi: 10.5603/ FM.2014.0028, indexed in Pubmed: 24902098.

7. Bardeen C. Development and variation of the nerves and the musculature of the inferior extremity and of the neighboring regions of the trunk in man. Am J Anat. 1906; 6(1): 259-390, doi: 10.1002/aja.1000060108.

8. Bergman R, Afifi A, Miyauchi R. Illustrated encyclopedia of human anatomic variations. Anatomy Atlas 2017.

9. Blasi M, de la Fuente J, Martinoli C, et al. Multidisciplinary approach to the persistent double distal tendon of the biceps brachii. Surg Radiol Anat. 2014; 36(1): 17-24, doi: 10.1007/s00276-013-1136-y, indexed in Pubmed: 23708377.

10. Cucca YY, McLay SVB, Okamoto T, et al. The biceps brachii muscle and its distal insertion: observations of surgical and evolutionary relevance. Surg Radiol Anat. 2010; 32(4): 371-375, doi: 10.1007/s00276-009-0575-y, indexed in Pubmed: 19847376.

11. Dong Q, Jacobson JA, Jamadar DA, et al. Entrapment neuropathies in the upper and lower limbs: anatomy and MRI features. Radiol Res Pract. 2012; 2012: 230679, doi: 10.1155/2012/230679, indexed in Pubmed: 23125929.

12. Le Double A. Traité des variations du système musculaire de l'homme et de leur signification au point de vue de l'anthropologie zoologique. Schleicher frères, Paris 1897. 
13. El-Naggar MM, Al-Saggaf S. Variant of the coracobrachialis muscle with a tunnel for the median nerve and brachial artery. Clin Anat. 2004; 17(2): 139-143, doi: 10.1002/ ca.10213, indexed in Pubmed: 14974102.

14. Garbelotti SA, Marques SR, Rocha PR, et al. An unusual case of accessory head of coracobrachialis muscle involving lateral cord of brachial plexus and its clinical significance. Folia Morphol. 2017; 76(4): 762-765, doi: 10.5603/FM.a2017.0033, indexed in Pubmed: 28353299.

15. Greig HW, Anson BJ, Budinger JM. Variations in the form and attachments of the biceps brachii muscle. Q Bull Northwest Univ Med Sch. 1952; 26(3): 241-244, indexed in Pubmed: 14957982.

16. Gruber W. Die Musculi subscapulares (major et minor) und die neuen supernumären Schultermuskel des Menschen. Máemoires de I'Acadáemie Impáeriale des Sciences de Saint Páetersbourg par Divers Savans et Lus dans ses Assembláees, 4th ed, Sankt Petersburg 1859.

17. Ilayperuma I, Nanayakkara G, Palahepitiya N. Incidence of humeral head of biceps brachii muscle: anatomical insight. Int J Morphol. 2011; 29(1): 221-225, doi: 10.4067/s071795022011000100037.

18. Iwanaga J, Singh V, Ohtsuka A, et al. Acknowledging the use of human cadaveric tissues in research papers: Recommendations from anatomical journal editors. Clin Anat. 2021; 34(1): 2-4, doi: 10.1002/ca.23671, indexed in Pubmed: 32808702.

19. Jeong JY, Park SM, Park YE, et al. Morphological classification of anatomical variants of the intra-articular portion of the long head of the biceps brachii tendon and analysis of the incidence and the relationship with shoulder disease for each subtype. J Orthop Surg (Hong Kong). 2017; 25(3): 1-6, doi: 10.1177/2309499017742207, indexed in Pubmed: 29157108.

20. De Jesus R, Dellon AL. Historic origin of the "Arcade of Struthers". J Hand Surg Am. 2003; 28(3): 528-531, doi: 10.1053/jhsu.2003.50071, indexed in Pubmed: 12772116.

21. Kopuz C, Sancak B, Ozbenli S. On the incidence of third head of biceps brachii in Turkish neonates and adults. Acta Anat Nippon. 1999; 74(3): 301-305, indexed in Pubmed: 10429374.

22. Kosugi K, Shibata S, Yamashita H. Supernumerary head of biceps brachii and branching pattern of the musculocutaneus nerve in Japanese. Surg Radiol Anat. 1992; 14(2): 175-185, doi: 10.1007/BF01794898, indexed in Pubmed: 1641744.

23. Landa J, Bhandari S, Strauss EJ, et al. The effect of repair of the lacertus fibrosus on distal biceps tendon repairs: a biomechanical, functional, and anatomic study. Am J Sports Med. 2009; 37(1): 120-123, doi: 10.1177/0363546508324694, indexed in Pubmed: 19029314.

24. Loukas M, Aqueelah H. Musculocutaneous and median nerve connections within, proximal and distal to the coracobrachialis muscle. Folia Morphol. 2005; 64: 101-108.

25. Macalister A. Additional observations on muscular anomalies in human anatomy. Transcations R Irish Acad. 1875; 25: 1-134.

26. Macalister A. Observations on the mucular variations in the human anatomy. Third series with a catalogue of the principal muscular variations hitherto published. Trans Rov Irish Acad Sci. 1875; 25: 1-134.
27. Meyer $P$, Lintingre $P F$, Pesquer $L$, et al. The median nerve at the carpal tunnel ... and elsewhere. J Belg Soc Radiol. 2018; 102(1): 17, doi: 10.5334/jbsr.1354, indexed in Pubmed: 30039031.

28. Moore K, Arthur F, Dalley I. Clinically Oriented Anatomy, 7th ed. Lippincott Williams\&Wilkins 2013.

29. Nayak SR, Prabhu LV, Sivanandan R. Third head of biceps brachii: A rare occurrence in the Indian population. Ann Anat. 2006; 188(2): 159-161, doi: 10.1016/j. aanat.2005.10.004, indexed in Pubmed: 16551013.

30. Olewnik $\measuredangle$, Karauda P, Gonera B, et al. Impact of plantaris ligamentous tendon. Sci Rep. 2021; 11(1): 4550, doi: 10.1038/s41598-021-84186-w, indexed in Pubmed: 33633305.

31. Olewnik $Ł$, Kurtys K, Gonera B, et al. Proposal for a new classification of plantaris muscle origin and its potential effect on the knee joint. Ann Anat. 2020; 231: 151506, doi: 10.1016/j.aanat.2020.151506, indexed in Pubmed: 32173563.

32. Olewnik $\measuredangle$, Podgórski $M$, Polguj $M$, et al. Anatomical variations of the pronator teres muscle in a Central European population and its clinical significance. Anat Sci Int. 2018; 93(2): 299-306, doi: 10.1007/s12565-017-0413-y, indexed in Pubmed: 28849397.

33. Olewnik $Ł$, Zielinska N, Gołek $Ł$, et al. Is it the coracobrachialis superior muscle, or is it an unidentified rare variant of coracobrachialis muscle? Surg Radiol Anat. 2021; 43(10): 1581-1586, doi: 10.1007/s00276-021-02773-y, indexed in Pubmed: 34037825.

34. Olewnik $Ł$, Zielinska N, Karauda P, et al. The co-occurrence of a four-headed coracobrachialis muscle, split coracoid process and tunnel for the median and musculocutaneous nerves: the potential clinical relevance of a very rare variation. Surg Radiol Anat. 2021; 43(5): 661-669, doi: 10.1007/s00276-020-02580-x, indexed in Pubmed: 32979058.

35. Olewnik $t$, Paulsen F, Tubbs RS, et al. Potential compression of the musculocutaneous, median and ulnar nerves by a very rare variant of the coracobrachialis longus muscle. Folia Morphol. 2021; 80(3): 707-713, doi: 10.5603/FM.a2020.0085, indexed in Pubmed: 32844391.

36. Podgórski M, Olewnik $Ł$, Rusinek M, et al. 'Superior biceps aponeurosis': Morphological characteristics of the origin of the short head of the biceps brachii muscle. Ann Anat. 2019; 223: 85-89, doi: 10.1016/j.aanat.2019.01.014, indexed in Pubmed: 30797975.

37. Rodríguez-Niedenführ M, Vázquez $T$, Choi $D$, et al. Supernumerary humeral heads of the biceps brachii muscle revisited. Clin Anat. 2003; 16(3): 197-203, doi: 10.1002/ ca.10060, indexed in Pubmed: 12673814.

38. Schwerdtfeger L, Pascoe M, Clapp T. High incidence of a third head of biceps brachii in females. Transl Res Anat. 2018; 12: 25-27, doi: 10.1016/j.tria.2018.08.001.

39. Snoeck $O$, Lefèvre $P$, Sprio $E$, et al. The lacertus fibrosus of the biceps brachii muscle: an anatomical study. Surg Radiol Anat. 2014; 36(7): 713-719, doi: 10.1007/s00276013-1254-6, indexed in Pubmed: 24414231.

40. Testut L. Les anomalies musculaires chez I' Homme, expliquées par la anatomie comparée. Leur importance en anthropologie. G Masson, Paris 1884. 
41. Theile F. Traité de Myologie. Baillière, Paris 1843.

42. Wood J. On human muscular variations and their relation to comperative anatomy. J Anat Physiol. 1867: 44-59.

43. Yershov D, Hudák R. Unusual variation of the biceps brachii with possible median nerve entrapment. Prague Med Rep. 2015; 116(2): 167-172, doi: 10.14712/23362936.2015.55, indexed in Pubmed: 26093671.

44. Zhou M, Ishizawa A, Akashi $H$, et al. Bilateral accessory heads of biceps brachii muscle coexisting with brachioradial artery passing between two layers of atypical bicipital aponeurosis. Transl Res Anat. 2021; 25: 100134, doi: 10.1016/j.tria.2021.100134.

45. Zielinska N, Olewnik $Ł$. Six-headed coracobrachialis muscle. Folia Morphol. 2022; 81(3): 809-813, doi: 10.5603/FM.a2021.0082, indexed in Pubmed: 34608984.

46. Zielinska N, Olewnik $Ł$, Karauda P, et al. A very rare case of an accessory subscapularis muscle and its potential clinical significance. Surg Radiol Anat. 2021; 43(1): 19-25, doi: 10.1007/ s00276-020-02531-6, indexed in Pubmed: 32656573.

47. Zielinska N, Tubbs RS, Podgórski M, et al. The subscapularis tendon: A proposed classification system. Ann Anat. 2021; 233: 151615, doi: 10.1016/j.aanat.2020.151615, indexed in Pubmed: 33068734.

48. Żytkowski A, Tubbs R, Iwanaga J, et al. Anatomical normality and variability: Historical perspective and methodological considerations. Transl Res Anat. 2021; 23: 100105, doi: 10.1016/j.tria.2020.100105. 